\title{
Influence of Different Smashing Methods on Biogas Generation Effect in Dry Fermentation of Sugarcane Leaves
}

\section{Li Zunxiang, Jiao Jing*, Wang Shuo, Du Jihua, Huang Xiaohong, Wang Jinli, Guo Changjin}

\author{
Institute of Agricultural Machinery, Chinese Academy of Tropical Agricultural Sciences \\ (CATAS),Zhanjiang 524091, Guangdong, P.R.China
}

1192187600@qq.com, eddweiss@163.com,wangshuo3564@126.com

\begin{abstract}
Key words: smashing method; dry anaerobic fermentation; biogas
Abstract: In this study, sugarcane leaves were used as the raw material. Three methods (cutting, rolling \& cutting, and hammering) were used to smash sugarcane leaves for dry fermentation. The influence of different smashing methods on biogas generation by dry fermentation of sugarcane leaves was analyzed from the aspects of smashing property, characteristics and biogas generation property. The results show that hammering grinder is superior to rolling \& cutting grinder and cutting grinder in terms of mean smashing time, mean non-smashing rate, mean over-smashing rate and mean smashing width. The total biogas output of hammering method is the maximum, but the effect difference with cutting method and rolling \& cutting method is no significant.
\end{abstract}

\section{Introduction}

The raw materials of dry fermentation of biogas are solid organic wastes (total solid content is above $20 \%$ ). Anaerobic bacteria decompose solid organic wastes into $\mathrm{CH}_{4}, \mathrm{CO}, \mathrm{H}_{2} \mathrm{~S}$ and other gases. Compared with wet fermentation, the advantages of dry fermentation include water conservation, saving the man-hour for biogas digester management, high volume gas productivity, digester volume reduction and small pollutant discharge. So, it is a promising way to comprehensively utilize agricultural wastes.

Sugarcane leaves are the residues after sugarcanes are harvested, accounting for $12 \%-20 \%$ of sugarcane output generally [2]. In the tropical zone of south China, annual total amount of waste sugarcane leaves is about 27 million tons [3], with the features of high output, concentrated producing area, purchase easiness, low cost and high nutritive value. The test results show that cellulose content of sugarcane leaves is $52.30 \%$. Carbon content of sugarcane leaves is $10 \%$ higher than that of cornstalks, but the nitrogen content is close. So, sugarcane leaf is a good raw material for biogas production [4]. Since cellulose of sugarcane leaves is coated by xylogen and hemicellulose, and it is not easy for microorganism to degrade xylogen, cellulose decomposition speed is slow. Thus, pretreatment must be done before the fermentation. Smashing method is an important factor influencing dry fermentation. With different smashing methods, the form of fermentation materials is also different. Besides, fermentation duration, biogas output and the form of biogas residue are also different. The influence of smashing methods on dry fermentation of sugarcane leaves is studied to achieve scientific control of dry fermentation conditions, so this study has important significance for guiding dry fermentation.

At present, among the smashing machines for sugarcane leaves in the tropical zone of south China, there are three forms of grinders according to smashing methods and means, including cutting grinder, rolling \& cutting grinder and hammering grinder. in this study, the three smashing methods were compared to find out the method suitable for pretreatment of sugarcane leaves so as to improve transformation efficiency of crops, increase biogas output and shorten the startup time. 


\section{Materials and methods}

Experimental materials. Raw materials: sugarcane leaves were collected from Huguang Farm in Zhanzhang City. Before smashing, the mean length of sugarcane leaves was $600 \mathrm{~mm}$ and the mean width was $15 \mathrm{~mm}$. The pig manure came from Huguang Farm in Zhanzhang City, with the total solid content of $26.57 \%$. The inoculum was the enrichment from moderate-temperature dry anaerobic fermentation of sugarcane leaves and pig manure. The enrichment duration exceeded two months, and the total solid mass fraction was 5\%. Other materials included urea and water.

Experimental devices. Biogas fermentation tank which is researched and developed independently was used as the experiment device. It consists of the body, heating sheet, insulating layer, thermal detector and gas flowmeter. It is characterized by convenient and fast opening, good airtightness, stable constant temperature and accurate measurement.

Cutting grinder: power $3 \mathrm{KW}$, motor speed $1340 \mathrm{r} / \mathrm{min}$; rolling \& cutting grinder: power $7.5 \mathrm{KW}$, motor speed $1440 \mathrm{r} / \mathrm{min}$; hammering grinder: power $5.5 \mathrm{KW}$, motor speed $1440 \mathrm{r} / \mathrm{min}$.

Experimental methods. Total solid was measured with oven drying method; total carbon was measured with $\mathrm{K}: \mathrm{Cr}_{2} \mathrm{O}$ heat resource method; total nitrogen was measured with Kjeldahl determination; methane content WAS MEASURD with biogas analyzer.

Under the condition of $1 \mathrm{~kg}$ feeding amount, mean smashing time, mean collection amount after smashing, mean loss rate, mean over-smashing rate, mean non-smashing rate, mean length and width after smashing of three methods were figured out.

The smashed sugarcane leaves were mixed with pig manure with proper amount of water according to the dry matter ratio of $1: 1 /$ proper amount of water was added according to the moisture content of $80 \%$. The mixture was composed for $7 \mathrm{~d}$ under aerobic condition, and then $30 \%$ $(\mathrm{v} / \mathrm{v})$ inoculum was added. Ammonium bicarbonate was used to adjust the carbon nitrogen ratio (about 25:1). After even stirring, the mixture was put in the tank for anaerobic fermentation for 30d.

\section{Results and analysis}

Analysis of smashing property of different smashing methods. Under the condition of $1 \mathrm{~kg}$ feeding amount, the smashing properties of different smashing methods were analyzed from the aspects of mean smashing time, mean collection amount after smashing, mean loss rate, mean over-smashing rate, mean non-smashing rate, mean length and width after smashing.

Mean smashing time is one of important indicators to investigate the property of a grinder. According to Table 1, hammering method needs the shortest time. It saves $53.01 \%$ of time, compared with cutting method and saves $47.56 \%$ of time, compared with rolling \& cutting method. Cutting method shows the highest mean collection amount $(97.36 \%)$, followed by hammering method and rolling \& cutting method. The comparison of mean non-smashing rate indicates that hammering grinder has the best effect, and all materials were completely smashed. The effect of rolling \& cutting grinder is better than that of cutting grinder. In the pretreatment process of physical smashing of sugarcane leaves, finer sugarcane leaves are more beneficial to destroy xylogen and hemicellulase in the cellulose an to improve use ratio and biogas production rate of sugarcane leaves. The analysis of mean length and width after smashing shows hammering grinder has the best effect. 
Table 1 Comparison of experimental data of three different smashing methods

\begin{tabular}{|c|c|c|c|c|c|c|c|}
\hline $\begin{array}{c}\text { Smashing } \\
\text { method }\end{array}$ & $\begin{array}{c}\text { Mean } \\
\text { smashing } \\
\text { time/s }\end{array}$ & $\begin{array}{l}\text { Mean collecting } \\
\text { amount after } \\
\text { smashing / kg }\end{array}$ & $\begin{array}{c}\text { Mean } \\
\text { loss rate } \\
\quad / \%\end{array}$ & $\begin{array}{c}\text { Mean } \\
\text { over-sma } \\
\text { shing rate } \\
\quad \% \%\end{array}$ & $\begin{array}{c}\text { Mean } \\
\text { non-smashi } \\
\text { ng rate } / \%\end{array}$ & $\begin{array}{l}\text { Mean length } \\
\text { after smashing } \\
\text { /mm }\end{array}$ & $\begin{array}{l}\text { Mean width } \\
\text { after smashing } \\
\text { /mm }\end{array}$ \\
\hline Cutting & 82.0909 & 0.9736 & 2.6364 & 0 & 4.7273 & 43.6364 & 9.8636 \\
\hline $\begin{array}{c}\text { Rolling \& } \\
\text { cutting }\end{array}$ & 73.5455 & 0.8736 & 12.6364 & 4.4545 & 3.9091 & 44.5455 & 3.6364 \\
\hline Hammering & 38.5736 & 0.9536 & 4.6364 & 4.9091 & 0 & 40.4545 & 3.5 \\
\hline
\end{tabular}

Influence of different smashing methods on form of sugarcane leaves before and after fermentation. As shown in Fig.1, hammering method presents the best decomposition effect. After the fermentation, there is almost no sugarcane leaf with the original shape, followed by cutting method and rolling \& cutting method.

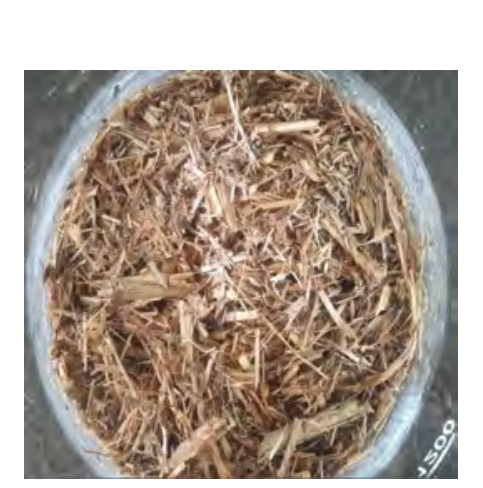

Hammering

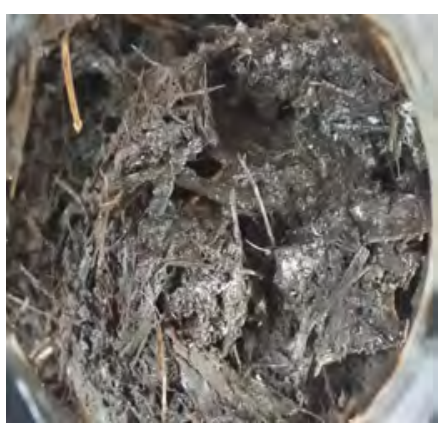

Before fermentation

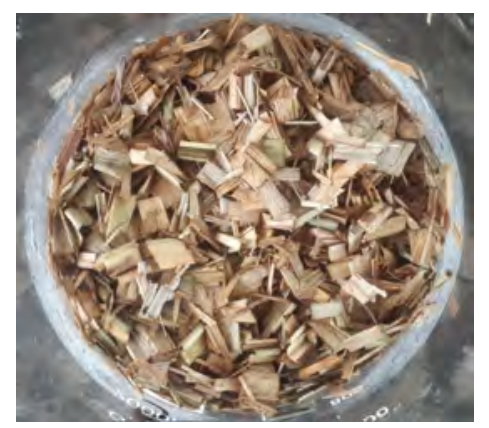

Cutting

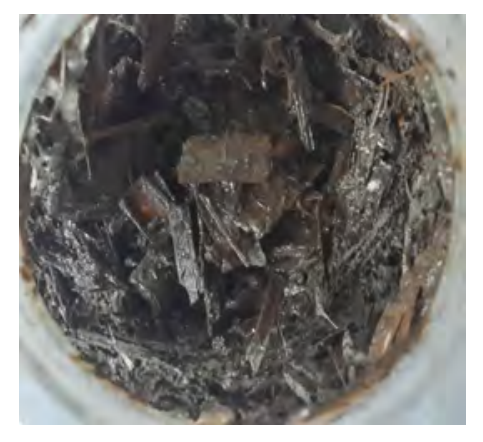

After fermentation

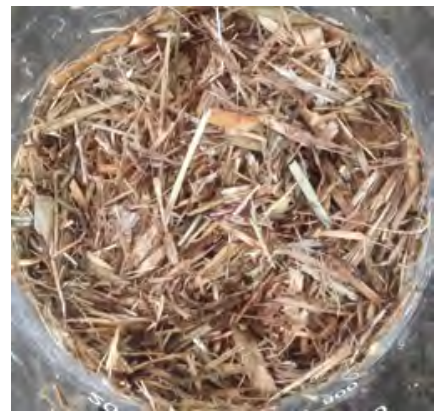

Rolling \& cutting

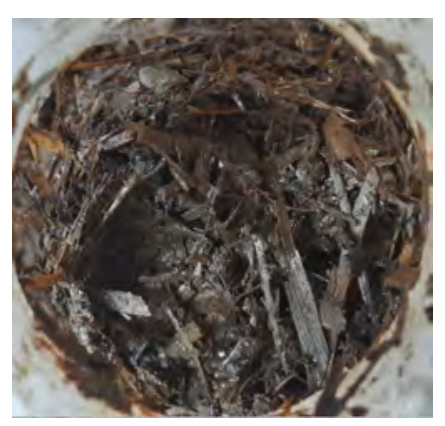

Fig.1 Comparison of different smashing methods before and after fermentation of sugarcane leaves

Influence of different smashing methods on total biogas output after fermentation of sugarcane leaves. As shown in Fig.2, hammering group presents the highest biogas output $(23595.09 \mathrm{~mL})$ in $30 \mathrm{~d}$, followed by cutting group $(22533.25 \mathrm{~mL})$ and rolling \& cutting group (20685.44mL). Duncan's extremum difference analysis was adopted for significance analysis of total biogas output of three smashing methods. The results show the three smashing methods have no significant difference in total biogas output $(\alpha=0.05)$. 


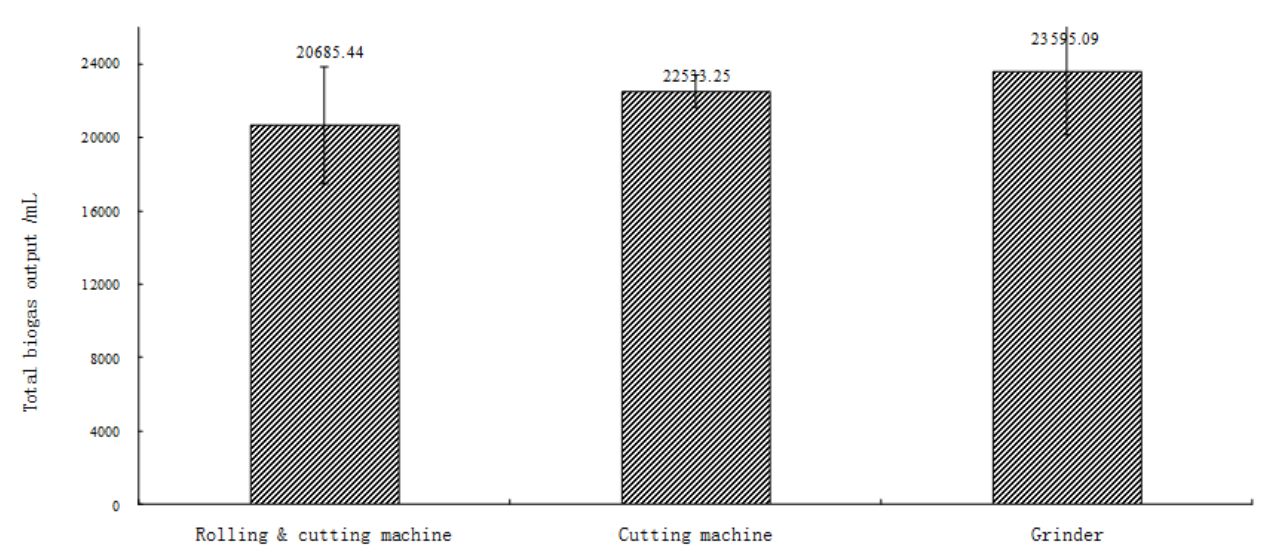

Fig.2. Influence of different smashing methods on total biogas output

\section{Conclusion}

The smashing property of rolling \& cutting method, cutting method and hammering method was analyzed from mean smashing time, mean non-smashing rate, mean over-smashing rate and mean smashing width etc. The results show hammering grinder is better than rolling \& cutting grinder in terms of mean smashing time, mean non-smashing rate, mean over-smashing rate and mean smashing width etc., so it is more suitable for pretreatment of sugarcane leaves in the tropical zone.

The influence of three smashing methods on biogas production effect was analyzed. The results indicate that hammering method has the highest total biogas output. Duncan's extremum difference analysis was adopted for significance analysis of total biogas output of three smashing methods. The results show the three smashing methods have no significant difference in biogas production effect.

In one word, hammering method is superior to rolling \& cutting method and cutting method in terms of smashing time, smashing degree, total biogas output and methane content, but the difference is not significant. Thus, energy consumption analysis should be carried out to provide more all-round data for engineering application.

\section{Acknowledgements}

This project is supported by Guangdong provincial-level science and technology planning program (2015A020209009).

\section{References}

[1] Jiao Jing, Wang Jinlin and Deng Yiguo et al., Effect of ratios of manure to straw on sugarcane leaves dry anaerobic fermentation for biogas production [J]. Guangdong Agricultural Sciences, Vol.37(1), p.51-54 (2010).

[2] Huo Lili, Meng Haibo, and Tian Yishui et al., Experimental study on physical property of smashed crop straw [J]. Transactions of the Chinese Society of Agricultural Engineering, Vol.11, p.189-195 (2012).

[3] Bian Yongcun, The Comparative Study of the Effect on Dry Anaerobic Fermentation for Corn Stalks with Different Pretreatment Methods [D]. Shenyang: Shenyang Institute of Aeronautical Engineering, (2010).

[4] Zheng Yong, Wang Gang and Wang Jinli, Development of a Small Horizontal Grinder of Sugarcane Leaves [J]. Chinese Agricultural Mechanization, Vol.2, p.98-100 (2011). 
[5] Wang Liping, Research of Design Theory for Composite Starw Grinder [D]. Harbin: Northeast Forestry University, (2010).

[6] Chen Yongsheng, Zhu Dewen and Qu Haoli et al., Materials Pretreatment Process and Equipment Technology of the Large and Medium-sized Biogas Projects [J]. Chinese Agricultural Mechanization, Vol.6, p.73-78 (2010).

[7] Ye Yuanwei, Key Technique Research about Pretreatment Pulp Machine of Sugarcane Leaves' Fermentation [D]. Haikou: University Of Hainan, (2012). 